\title{
Exploring the Limitations on RFID Technology in Traceability Systems at Beverage Factories
}

\author{
Isabel Expósito and Iñigo Cuiñas \\ Departamento de Teoría do Sinal e Comunicacións, Universidade de Vigo, 36310 Vigo, Spain \\ Correspondence should be addressed to Iñigo Cuiñas; inhigo@uvigo.es
}

Received 27 March 2013; Revised 1 June 2013; Accepted 5 June 2013

Academic Editor: Luca Catarinucci

Copyright ( 2013 I. Expósito and I. Cuiñas. This is an open access article distributed under the Creative Commons Attribution License, which permits unrestricted use, distribution, and reproduction in any medium, provided the original work is properly cited.

The application of RFID in traceability of products in beverage factories is analyzed in terms of the electromagnetic conditions defined by the massive presence of metallic elements and liquids. Various experiments are reported to determine the maximum reading range from RFID tags installed on tanks or to read RFID information around bottles, both empty and full of wine, trying to put in context the possible problems that could appear when installing an RFID-based traceability system within a winery, a brewery, or any other beverage factory.

\section{Introduction}

During last years, the development of radio frequency identification (RFID) technologies has been fast and their applications grow in parallel to the reduction of costs [1]. A lot of companies and even some European projects proposed the use of RFID technology to build full traceability systems, substituting barcodes in some applications but extending the functionalities to the complete production chain [2-4]. The development of international standards, such as EPC global [5], has given an additional impulse to further spread this technology. Reading some reports, it would seem that the RFID is the solution for all traceability problems. The reason to propose the use of this technology for traceability purposes is that it allows the unequivocal identification of each agent along a production chain (machines, containers, products, and even operators) and a fast and accurate registration of all of them when being involved at each step of the process. Thus, the reconstruction of a product history becomes no more than a query at the database storing all the data previously collected in the factory.

The wide diversity of tags available in the market allows the use of RFID in a large range of applications. Tags could even be printed directly to the final product by means of inkjet-printing technology [6]. Passive RFID tags are the most used tracing systems due to their lower cost, especially at item level. Several frequencies are also available. The choice of the frequency will depend on the requirements of the applications (required reading range, environmental conditions, multitag reading, etc.).

The development of an RFID-based traceability system in a beverage factory (wine, liquors, sodas, etc.) presents some technical challenges due to the special considered environments: large metallic tanks, liquids, glass bottles, and so forth, all of them electromagnetic unfriendly elements. But the developments of such system could lead to improved benefits associated with reduction of time expenses, reduction of errors, and accuracy of the information. The objective of this paper is not only to present an implementation of an RFIDbased traceability and its advantages but also to isolate and evaluate the possible limitations due to the presence of liquid and metallic elements.

The paper is organized as follows. After this introduction, a brief description of related works occupies Section 2 . Section 3 is centered on the guidelines of a complete traceability system based on RFID technology. Then, the detection and analysis of limitations for RFID operation due to the environment characteristics are the focus of Section 4 , which is followed by the Conclusions section. 


\section{Related Works}

Previous examples of the implementation of RFID tracing systems in food supply chains can be found in the literature, even in scenarios with adverse propagation conditions [7-9].

When certain reading distance or multiple readings are required, UHF technology is commonly used. Previous studies have been performed to evaluate the theoretical limitations in the performance of UHF RFID tags [10], not only for tags working in far filed conditions but also for the ones designed to operate in near field [11], as they are less affected by the presence of liquids and metals. However comparative test shows that UHF far field tags can provide good performance also in critical environments. That is one of the reasons to use FF UHF tags in our research and also to allow the developed system to be in compliance with the EPCglobal standard. The benefits of the combined use of both RFID technology and EPCIS standards in supply chains have been also analyzed [12].

Some authors propose specific tag designs to highly overcome the limitations of UHF RFID tags in critical environments $[13,14]$ although our study was performed with commercial available RFID tags as it aims to test if their use is feasible in the nonelectromagnetic friendly environment of a winery, in order to minimize the costs of initial investment.

\section{RFID-Based Traceability System}

There are several reasons for a factory manager to implement a traceability system, both voluntary and compulsory. The mandatory reasons came from the legislation that controls quality or origin guarantee of the products. The voluntary ones arise from the conviction of a better organized and improved work along the production chain. Both reasons could be applied to many beverage factories: several wineries or whisky companies are involved in denominations of origin that force the adoption of traceability systems. Others are not forced to do that, but they produce added value liquors and need to guarantee consumers their quality.

Anyway, all the involved factories have something in common: the quality of the processes applied to the liquids (wines, liquors, and sodas) has to be certified, and all the related data are stored, to assure complete product traceability. The handled data include information regarding liquid analysis, treatments applied, equipment used in processing, and so forth. Previous to the RFID-based system implementation, the usual procedure was to store the data in register books and then manually copy the most important in digital registers (i.e., spreadsheets). The RFID-based approach aims to automatically collect all these information in digital supports and to develop applications to easily recover the data related to a specific product.

The processing stage is, by far, the most important one in beverage factories supply chain. It is the largest and most complex one, and the different processes performed in it will define the different characteristics and qualities of the products. That is, the processing phase of wine starts when the grapes collected arrive to the winery and it ends when the wine is bottled and stored, through a succession of actions: grapes classification, pressing, decantation, fermentation, blending, product treatments, conservation, and so forth. All the locations where the grapes and wine pass trough have to be identified in order to assure the traceability of wine. In each step of the processing phase, a lot of meaningful information is generated and has to be collected and stored in a database, especially those regarding chemical analysis and treatments performed. And something like this occurs at factories producing other beverages.

The RFID system designed in the presented research for a beverage company will allow easy data collection and digital storage of them, partly removing the current system of paper based registers and manual loading of data in spreadsheets. Along the whole processing stage Events will be generated and stored, so that the state of the product can be precisely controlled at each moment, and all the information related to the processes is easily accessible. Some assets are reused in different phases, so that a precise and unequivocal identification of them is required to ensure traceability. RFID tags will be attached to the different equipment used.

Two issues are solved with the RFID-based system: the automation of traceability data collection and their storage in digital supports and the quick access to traceability information at any point of the supply chain.

3.1. Automation of Traceability Data Collection and Their Storage in Digital Supports. At wine or liquor processing stage the amount of data handled is very large, and a precise control on them is needed, to assure a good quality and its traceability. As stated above, the registration of traceability data is typically done manually and then transferred to computer format using spreadsheets.

The first step, when developing a traceability system, is to perform a study of the business processes in the factory to identify the different steps in its supply chain and the information flow between them. Once the mandatory/optional information to be collected was defined, the points in the chain to do the capture are set.

The business processes are defined in terms of Events according to the EPCglobal standard [15]. We have used the Fosstrak EPCIS repository to store the Events, and we have run its access interfaces in a GlassFish application server [16]. The assets and locations involved and their relation to intermediate and final products are also identified. After collecting all the necessary requirements, the system design centered (HW and SW definitions) around two main points (Figure 1).

(i) Data Capturing. As all the locations and assets involved in raw and final products processing have to be identified in order to perform product traceability, they have been assigned an EPC code by tagging them with RFID labels. Some assets are reused in different phases, so that a precise and unequivocal identification of them is required to ensure traceability.

Then, a capture application for an RFID reader must be programmed to read those RFID tags and to introduce any other relevant data related to the production 


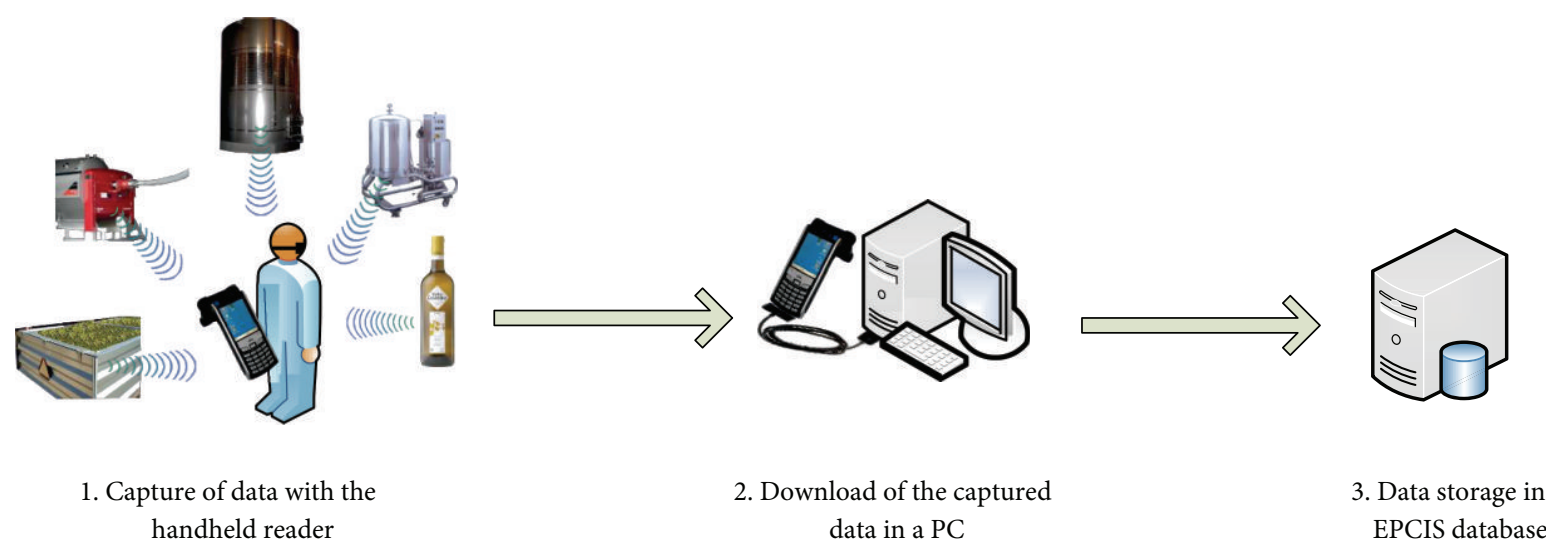

FIGURE 1: Schema of the data capturing process.

at each step of the supply chain. For each action performed one or several XMLs containing the generated EPCIS Events are built with all the collected information and stored in the handheld memory.

(ii) Database Data Storage. A PC desktop application is programmed to manage the communications with the EPCIS repository for information storage and recovery functions. The XMLs generated during data collection have to be copied from the handheld reader's memory to a PC. Then, by using one of the desktop application features, the data in the XMLs are sent to the EPCIS capture interface and stored in the repository. In this way we have all the pertinent data available in digital support (an MySQL database in a computer) available for consultation.

The RFID system designed will allow easy and fast data collection directly in digital support, removing paper based registers. At the same time the number of errors (and their associated costs) is reduced, and a better use of employees' time is achieved.

3.2. Quick Access to Traceability Information at Any Point of the Supply Chain. Currently, a high amount of spreadsheets should be checked for recovering traceability data, for example, in case they have been required by the competent authority or if there has been a recall.

The solution must be a desktop traceability application to track the wine at the winery. On the one hand it allows obtaining the complete traceability information of a bottle, through its batch number. On the other hand there is the possibility of querying for liquid information at any point of the supply chain, by using the tank number. Thus, the system makes the information sharing easier and also improves the visibility throughout the supply chain.

In addition, the RFID system allows linking unequivocally the liquid product with the data related to its production: performed processes, locations, environmental and chemical parameters, and so forth giving the producer a better control of product quality. So quality control and traceability are performed at the same time.

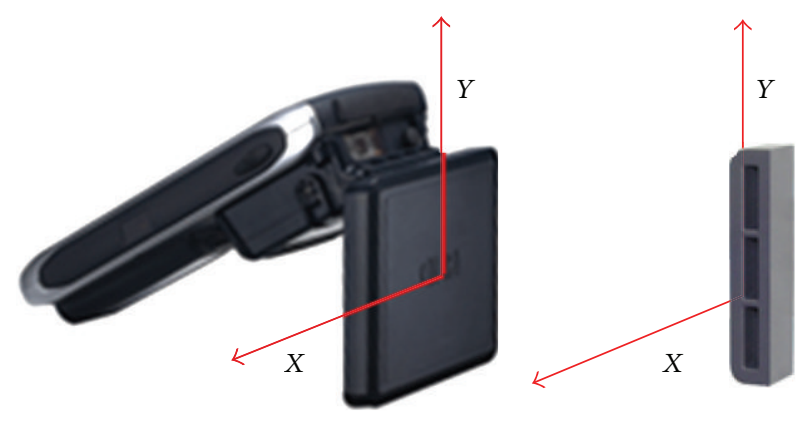

Figure 2: Coordinate system to establish a reference for the tag orientation.

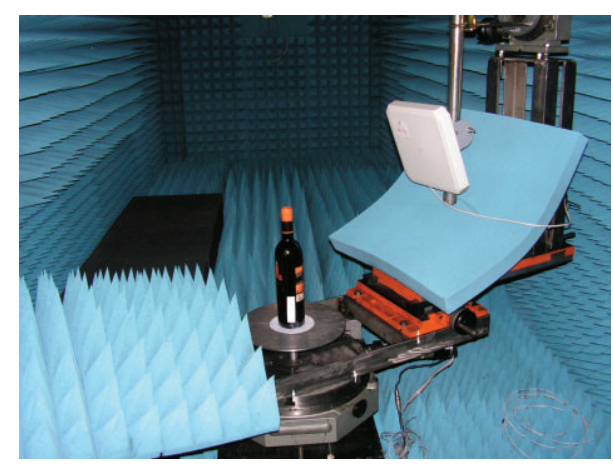

FIGURE 3: Setup for the measurements of received signal and reading arc around bottles.

\section{Identification and Analysis of RFID Limitations within a Beverage Factory}

The first step to identify the possible limitations when operating an RFID-based traceability system within a beverage factory is the reflection on the materials that (i) make especially the propagation of radio waves difficult and (ii) are also present in such factories.

It is well known that conductive materials generate isolation with respect to their shadowed areas and also induce strongly reflections of radio waves that beat the metallic 


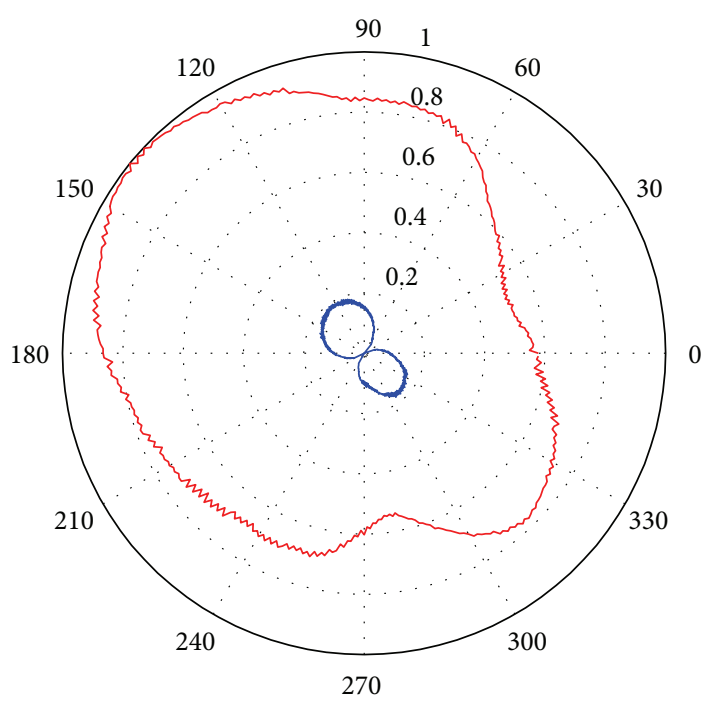

Empty bottle

- Full bottle

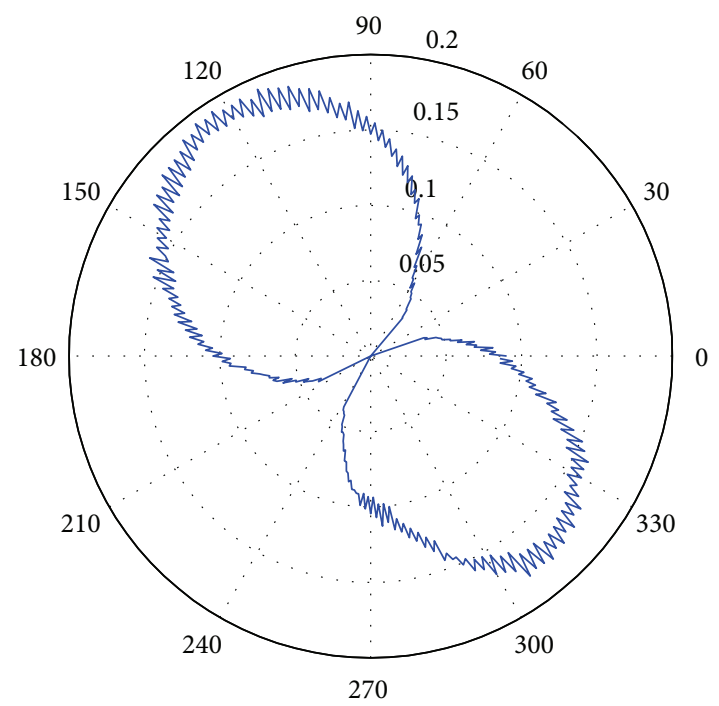

(b)

FIgURE 4: Percentage of received power, using tag 1, around bottle 2.

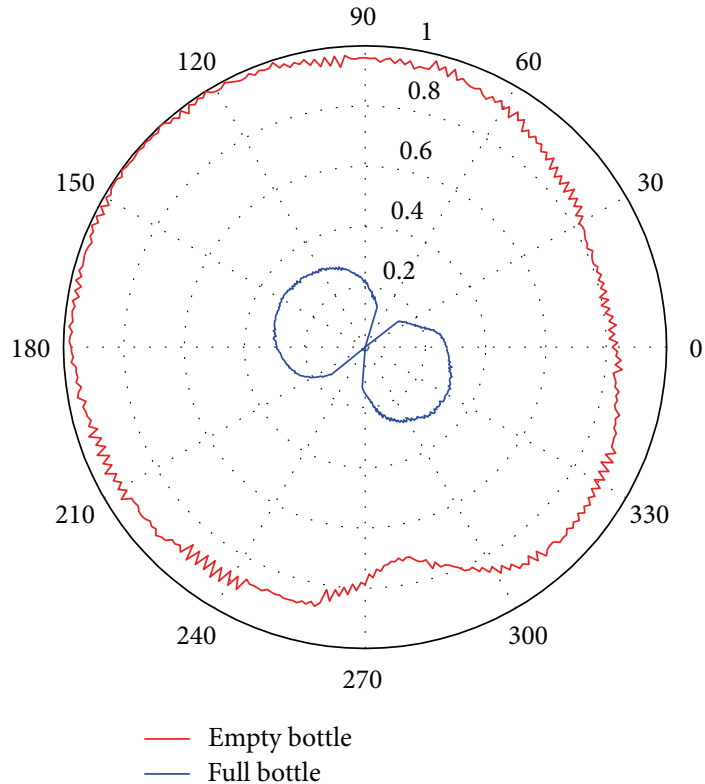

(a)

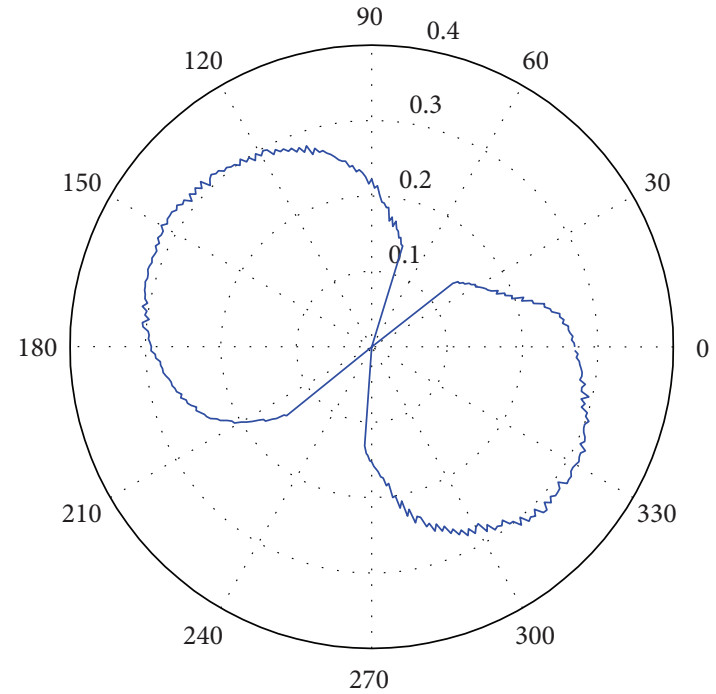

(b)

FIGURE 5: Percentage of received power, using tag 2, around bottle 2.

surface [17]. Radio wave propagation in factory buildings presents large multipath phenomena, directly related to building age, inventory, wall locations, and ceiling height [18]. Beverage factories are full of large metallic tanks, so it is expected to find a complicated electromagnetic ambience: important multipath phenomena and vast areas with no radio coverage. This absence of radio coverage could be solved by applying imaginative techniques as taking advantage of HVAC ducts [19].
Liquids are other unfriendly materials for electromagnetic activities, as propagation conditions could change or even disappear within such materials. Obviously, there are lots of liquids in beverage factories, and the air and surfaces humidities are also elevated. Besides that, most of the liquid products of such factories are commercialized in glass bottles, which depending on their conductivities could be complicated materials: scattering or attenuation phenomena could be induced around each individual bottle [20]. So, a set of 


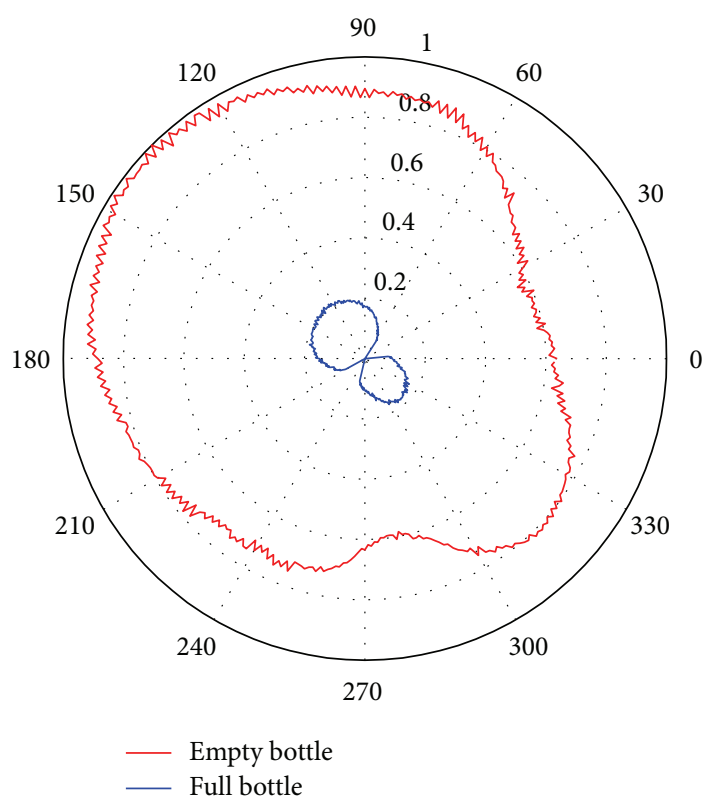

(a)

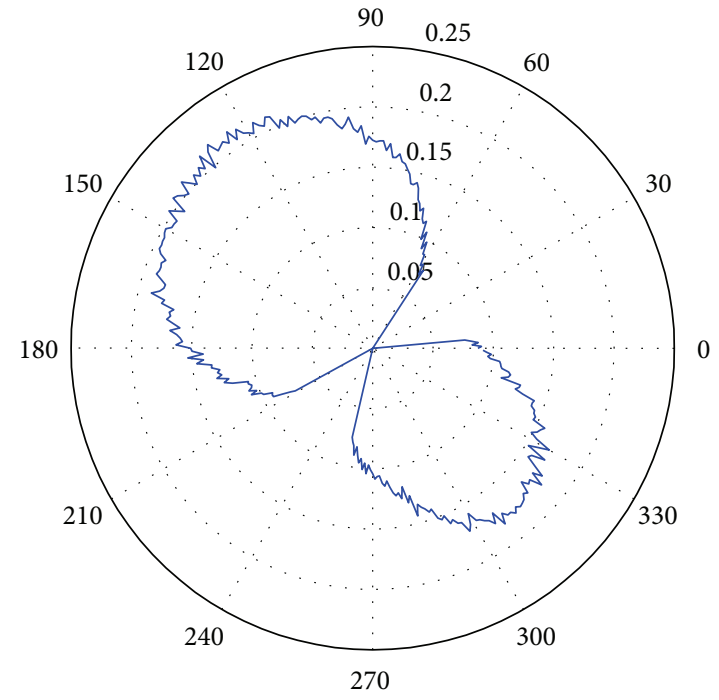

(b)

FIGURE 6: Percentage of received power, using tag 5, around bottle 2.

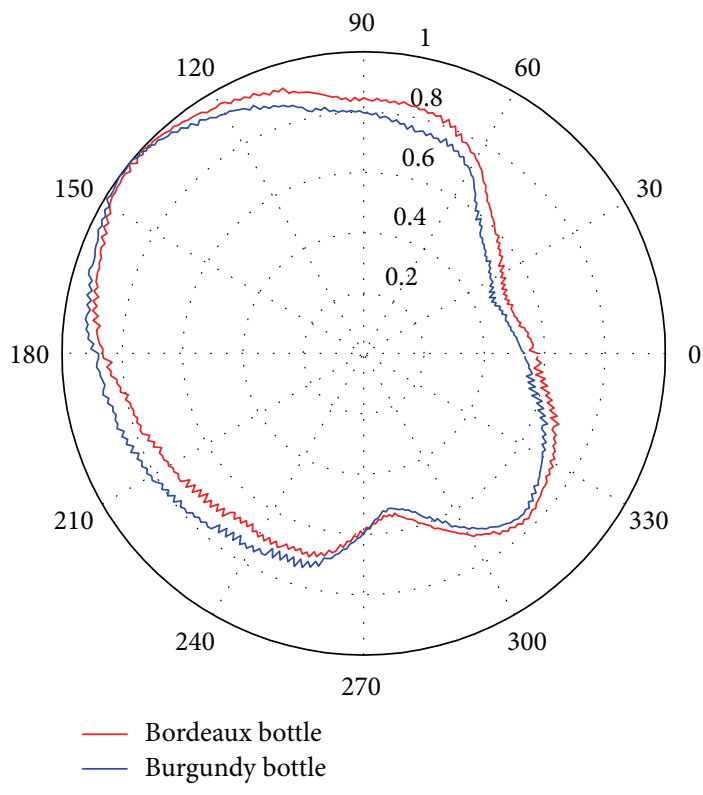

(a)

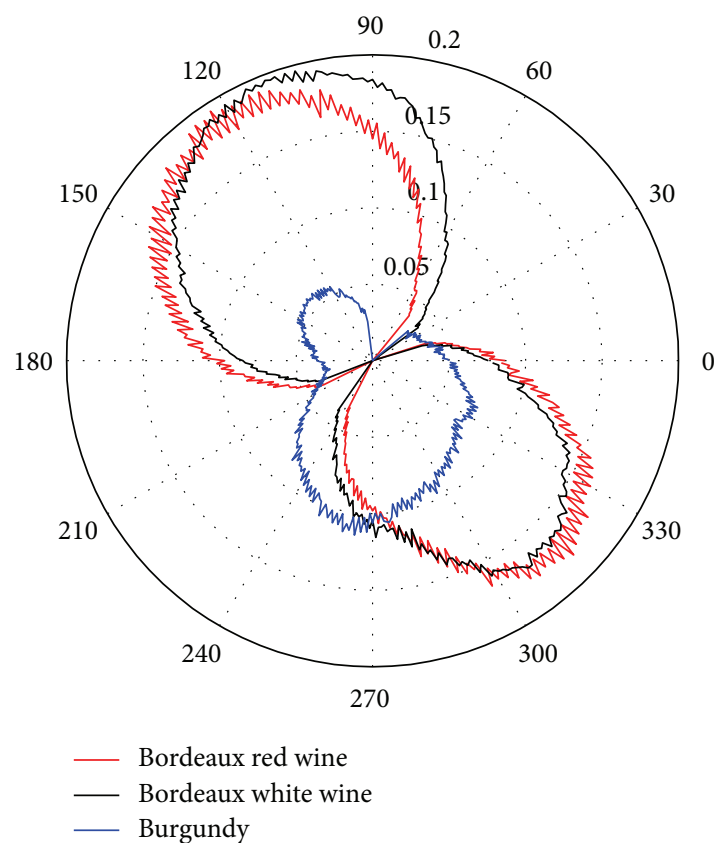

(b)

FIGURE 7: Comparison of the percentage of received power, using tag 1, around three bottles.

bottles would be a very difficult environment to be electromagnetically modeled.

4.1. Metallic Tanks. Several tests were performed to measure the maximum reading range of a tag attached to a wine tank. The tag used was the Confidex Halo [21], and its reading range attached to the tank was measured by using the ATID AT-570 handheld reader [22]. Although the antenna design for RFID tags is rapidly expanded [23] and there are special tag designs that would improve the radio performance isolating the tag from the surface where it is glued [24], this work is focused on commercial inexpensive tags, as they are the most accessible ones for RFID integrators. 
TABLE 1: Maximum reading distance of a tag glued on a metallic tank depending on its orientation.

\begin{tabular}{lc}
\hline Position to the vertical axis & Maximum reading range \\
\hline $0^{\circ} / 90^{\circ}$ on nonmetal surface & $162 \mathrm{~cm} / 160 \mathrm{~cm}$ \\
$0^{\circ}$ on metal surface & $81 \mathrm{~cm}$ \\
$30^{\circ}$ on metal surface & $78 \mathrm{~cm}$ \\
$60^{\circ}$ on metal surface & $73 \mathrm{~cm}$ \\
$90^{\circ}$ on metal surface & $53 \mathrm{~cm}$ \\
$120^{\circ}$ on metal surface & $53 \mathrm{~cm}$ \\
$150^{\circ}$ on metal surface & $73 \mathrm{~cm}$ \\
\hline
\end{tabular}

The measures were performed in such a way that the reader antenna and the tag were parallel to each other, according to the coordinate system indicated in Figure 2. Besides, the maximum reading distance was measured for several positions of the tag on the tank, indicated as an angle with respect to vertical direction $(Y)$, assuming cylindrical metallic tanks oriented with its axis along $Y$.

Table 1 shows the maximum reading range for each orientation of the tag in the tank and a measure of the reading range with the tag in a nonmetal surface (a wall) for comparison.

$0^{\circ}$ to the vertical axis (i.e., the tag is vertically installed) seems to be the best position for the tag (it can be read at up to $81 \mathrm{~cm}$ ). The difference in reading distance between this case and $90^{\circ}$ to the vertical axis, that is, horizontal installation (53 $\mathrm{cm}$ of reading range), may be due to the curvature of the tank, because the metal contact underneath tag is not uniform in its entire surface. This difference is minimal in the reference case maybe because the tag is attached to a flat surface.

It is interesting to observe that the presence of the metallic surface divides by two the maximum reading distance; that is, it degrades the performance of the RFID link.

4.2. Bottles. A radio electric measurement campaign involving different models of bottles, different kind of wines, various RFID tag designs, and several locations of the RFID tags has been performed within an anechoic chamber. As a difference with previous experiences, where researchers used tailor made setups [25], this measurement campaign has been developed with standard RFID reader. Figure 3 shows instant snapshot of the measurement campaign.

Measurements were made using the Alien ALR-9900 reader [26] and an Alien ALR-8611-AC antenna [27]. As the tests have been performed within an anechoic chamber, the use of only one type of RFID reader has no impact on the obtained results. Up to eight different tag models (Table 2) were tested looking for situations which would be common to most of them, depending on their adaptation to the electromagnetic conditions of the bottle. To assess whether the type of wine contained in the bottle and the shape of the bottle influence the measure, measurements have been made attaching tags in four bottles of different wines. To evaluate how much the signal is attenuated in the presence of liquid, the same measurements were made in two empty bottles in order to establish a reference.
We considered that, using individual bottles during the experiment, we could isolate the effects of the bottle and wine on the propagation conditions. When using various bottles at a time, it could be difficult to explain which effects are due to the wine and individual bottle and which are a consequence of multipath among the set of bottles.

Table 3 shows detailed information about the shape of the bottles. The distance between the center of the antenna and the center of the platform where the bottle is placed is $60 \mathrm{~cm}$, and the antenna is pointing to the bottle with an angle of $19^{\circ}$ with respect to the vertical axis.

The first results of the campaign show that the received power is reduced in all cases, due to the presence of the liquid, which also modifies the radiation pattern, as can be observed in Figures 4, 5, and 6. The maximum received power is reduced between $31 \%$ and $89 \%$ depending on the type of tag used, with a mean value of $63 \%$. In the same way the arc around the bottle where the reading of the tag is possible is also reduced, from $9 \%$ to $73 \%$, with a mean value of $28 \%$ (in only one of the combinations considered no reduction is observed).

Table 4 shows the percentage of reduction of received power when the wine is inside the bottle. As expected the tags on the filled bottles are not able to guarantee optimal performance, due to the attenuation of radio waves in the presence of liquids. Analyzing the results, it seems that the reduction in the power received from the tag due to the presence of liquid is more related to the type of tag used than to the shape of the bottle and the chemical characteristics of the liquid inside it, as the percentage values are quite similar, in most of the cases, for a given tag model. Only slight differences can be attributed to the specific chemical characteristics of wine, as happens with bottles 2 and 4, which, despite containing the two red wines, do not have the same percentage. The wines are under different denominations of origin.

When considering the arc around the bottle where the tag can be read, as indicated in Table 5, the model of tag used has a great influence on arc reduction, but, in some situations, for a given tag, the reduction is different, and this could come from the shape of the bottle or from the content inside it.

(i) For tag 2 and tag 4 the arc at which the reading is possible is smaller for the bottle with Burgundy shape.

(ii) In the case of tag 3 the differences in reading arc appear to be caused by the type of wine (better results for white wine).

When choosing the best model to be used, the results showed in both tables should be considered together. For example, although $\operatorname{tag} 7$ was the one with less reduction in the receiving power, the reading arc is reduced to a half; tag 8 allows less receiving power than tag 7 but the reading arc is the best. So, for an application where the relative position between the tag and the reader cannot be controlled with precision, tag 8 would be a better solution.

Figure 7 shows a comparison of the radiation pattern for a specific tag and the two bottle shapes analyzed. If the bottle is empty, the radiation pattern for the two shapes is very similar, but we can appreciate a great difference when the bottle is full 
TABLE 2: Characteristics of the RFID tags used in the tests.

\begin{tabular}{|c|c|c|c|c|c|c|c|c|}
\hline Tag & 1 & 2 & 3 & 4 & 5 & 6 & 7 & 8 \\
\hline Chip & $\begin{array}{c}\text { Impinj } \\
\text { Monza } 3\end{array}$ & $\begin{array}{l}\text { NXP U-Code } \\
\text { G2XL }\end{array}$ & $\begin{array}{l}\text { NXP U-Code } \\
\text { G2XL }\end{array}$ & Impinj Monza 3 & Alien Higgs-3 & Alien Higgs-3 & Alien Higgs-3 & Alien Higgs-3 \\
\hline Size $(\mathrm{mm})$ & $97 \times 27$ & $97 \times 15$ & $80 \times 25$ & $54 \times 34$ & $98 \times 12$ & $73.5 \times 21$ & $47 \times 50$ & $97.5 \times 23$ \\
\hline Inlay & \multicolumn{8}{|c|}{ Paper } \\
\hline Prot. & \multicolumn{8}{|c|}{ EPC Class 1 Gen 2} \\
\hline Freq. & \multicolumn{8}{|c|}{$860-960 \mathrm{MHz}$} \\
\hline
\end{tabular}

TABLE 3: Characteristics of the bottles of wine used in the tests.

\begin{tabular}{lcccccc}
\hline & Bottle 1 & Bottle 2 & Bottle 3 & Bottle 4 & Reference bottle 1 & Reference bottles 2, 3, and 4 \\
\hline Shape & Burgundy & Bordeaux & Bordeaux & Bordeaux & Burgundy & Bordeaux \\
Height & $30 \mathrm{~cm}$ & $30 \mathrm{~cm}$ & $32 \mathrm{~cm}$ & $31.5 \mathrm{~cm}$ & $30 \mathrm{~cm}$ & $31.5 \mathrm{~cm}$ \\
Neck length & $10.5 \mathrm{~cm}$ & $8.5 \mathrm{~cm}$ & $8.5 \mathrm{~cm}$ & $8.5 \mathrm{~cm}$ & $10.5 \mathrm{~cm}$ & $8.5 \mathrm{~cm}$ \\
Base diameter & $7.5 \mathrm{~cm}$ & $6.8 \mathrm{~cm}$ & $6.8 \mathrm{~cm}$ & $7 \mathrm{~cm}$ & $7.5 \mathrm{~cm}$ & $7 \mathrm{~cm}$ \\
Type of wine & White & Red & White & Red & - & - \\
\hline
\end{tabular}

TABLE 4: Percentage of reduction in the maximum received power due to the influence of wine.

\begin{tabular}{|c|c|c|c|c|c|c|c|c|}
\hline & Tag 1 & Tag 2 & Tag 3 & Tag 4 & Tag 5 & Tag 6 & Tag 7 & Tag 8 \\
\hline Bottle 1-white wine-Burgundy shape & $89 \%$ & $78 \%$ & $59 \%$ & $82 \%$ & $86 \%$ & $83 \%$ & $38 \%$ & $62 \%$ \\
\hline Bottle 2-red wine-Bordeaux shape & $81 \%$ & $68 \%$ & $80 \%$ & $76 \%$ & $78 \%$ & $81 \%$ & $31 \%$ & $62 \%$ \\
\hline Bottle 3 -white wine-Bordeaux shape & $80 \%$ & $70 \%$ & $68 \%$ & $78 \%$ & $80 \%$ & $80 \%$ & $42 \%$ & $62 \%$ \\
\hline Bottle 4-red wine-Bordeaux shape & $83 \%$ & $70 \%$ & $75 \%$ & $79 \%$ & $81 \%$ & $82 \%$ & $41 \%$ & $62 \%$ \\
\hline
\end{tabular}

TABLE 5: Percentage of reduction in the reading arc around the bottle due to the influence of wine.

\begin{tabular}{|c|c|c|c|c|c|c|c|c|}
\hline & Tag 1 & Tag 2 & Tag 3 & Tag 4 & Tag 5 & Tag 6 & Tag 7 & Tag 8 \\
\hline Bottle 1 -white wine-Burgundy shape & $16 \%$ & $67 \%$ & $45 \%$ & $65 \%$ & $28 \%$ & $13 \%$ & $40 \%$ & $16 \%$ \\
\hline Bottle 2-red wine-Bordeaux shape & $18 \%$ & $22 \%$ & $73 \%$ & $36 \%$ & $27 \%$ & $23 \%$ & $49 \%$ & $0 \%$ \\
\hline Bottle 3 -white wine-Bordeaux shape & $14 \%$ & $26 \%$ & $45 \%$ & $30 \%$ & $25 \%$ & $17 \%$ & $41 \%$ & $9 \%$ \\
\hline Bottle 4 -red wine-Bordeaux shape & $19 \%$ & $26 \%$ & $71 \%$ & $44 \%$ & $24 \%$ & $15 \%$ & $54 \%$ & $9 \%$ \\
\hline
\end{tabular}

TABLE 6: Maximum received signal and reading arc values at different tag heights.

\begin{tabular}{lcc}
\hline Position of tag's center & Arc width & Maximum (a.u.) \\
\hline $7 \mathrm{~cm}$ & $177^{\circ}$ & 1534.3 \\
$7.8 \mathrm{~cm}$ & $174^{\circ}$ & 1547.6 \\
$8 \mathrm{~cm}$ & $175^{\circ}$ & 1549.3 \\
$8.5 \mathrm{~cm}$ & $166^{\circ}$ & 1513.0 \\
$9 \mathrm{~cm}$ & $133^{\circ}$ & 1345.5 \\
$9.5 \mathrm{~cm}$ & $111^{\circ}$ & 1190.4 \\
$10 \mathrm{~cm}$ & $47^{\circ}$ & 930.1 \\
$10.5 \mathrm{~cm}$ & $96^{\circ}$ & 920.5 \\
$11 \mathrm{~cm}$ & $124^{\circ}$ & 1141.1 \\
$11.5 \mathrm{~cm}$ & $196^{\circ}$ & 1298.5 \\
$12 \mathrm{~cm}$ & $172^{\circ}$ & 1321.7 \\
$12.5 \mathrm{~cm}$ & $114^{\circ}$ & 1244.4 \\
$13 \mathrm{~cm}$ & $99^{\circ}$ & 1141.7 \\
$13.5 \mathrm{~cm}$ & $92^{\circ}$ & 1091.3 \\
\hline
\end{tabular}

of liquid. Such a difference does not exist when the bottles have the same shape but different content (red or white wine).

Besides, another test has been performed to choose the best height to place the tag along the bottle. During the tests, the tag is attached to the bottle with its center situated between 7 and $13.5 \mathrm{~cm}$ with respect to the bottom of the bottle, and this last one is placed at a fixed location in the center of the chamber (as already shown in Figure 3). For each position of the tag, the RFID antenna is moving along a 360-degree arc around the bottle location, centered at the bottle axis. The antenna stops at each degree, where 25 readings of the tag are performed.

Measurements have been performed with the same four bottles used in the previous experiment and two models of tags. Table 6 shows the width of the arc at which the reading is possible and the maximum value of received signal (RSSI measured by the RFID reader arbitrary units) in each position of the tag for one of the bottles (Bordeaux shape and white wine). The maximum distance between the tag and the reader antenna is reached when the tag lies on the rear side of the bottle. Table 7 presents this distance for the Bordeaux 
TABLE 7: Distance between the antenna and the center of the RFID tag.

\begin{tabular}{lcc}
\hline Position of tag's center & $\begin{array}{c}\text { Maximum } \\
\text { distance }\end{array}$ & $\begin{array}{c}\text { Minimum } \\
\text { distance }\end{array}$ \\
\hline $7 \mathrm{~cm}$ & $57.32 \mathrm{~cm}$ & $52.50 \mathrm{~cm}$ \\
$7.8 \mathrm{~cm}$ & $56.99 \mathrm{~cm}$ & $52.13 \mathrm{~cm}$ \\
$8 \mathrm{~cm}$ & $56.65 \mathrm{~cm}$ & $51.77 \mathrm{~cm}$ \\
$8.5 \mathrm{~cm}$ & $56.32 \mathrm{~cm}$ & $51.40 \mathrm{~cm}$ \\
$9 \mathrm{~cm}$ & $55.99 \mathrm{~cm}$ & $51.04 \mathrm{~cm}$ \\
$9.5 \mathrm{~cm}$ & $55.67 \mathrm{~cm}$ & $50.69 \mathrm{~cm}$ \\
$10 \mathrm{~cm}$ & $55.34 \mathrm{~cm}$ & $50.33 \mathrm{~cm}$ \\
$10.5 \mathrm{~cm}$ & $55.02 \mathrm{~cm}$ & $49.98 \mathrm{~cm}$ \\
$11 \mathrm{~cm}$ & $54.70 \mathrm{~cm}$ & $49.63 \mathrm{~cm}$ \\
$11.5 \mathrm{~cm}$ & $54.39 \mathrm{~cm}$ & $49.28 \mathrm{~cm}$ \\
$12 \mathrm{~cm}$ & $54.08 \mathrm{~cm}$ & $48.94 \mathrm{~cm}$ \\
$12.5 \mathrm{~cm}$ & $53.77 \mathrm{~cm}$ & $48.59 \mathrm{~cm}$ \\
$13 \mathrm{~cm}$ & $53.46 \mathrm{~cm}$ & $48.25 \mathrm{~cm}$ \\
$13.5 \mathrm{~cm}$ & $53.16 \mathrm{~cm}$ & $47.92 \mathrm{~cm}$ \\
\hline
\end{tabular}

shaped bottle with white wine. Such distance depends on the distance between the antenna and the bottle, the diameter of the bottom of the bottle, and the height at which the tag is glued. Minimum distance (tag on the front side) is also presented for comparison.

Results show that, in this case, the best position to put the tag is with its center between $7 \mathrm{~cm}$ and $8 \mathrm{~cm}$ away from the bottom of the bottle. For these distances the receiving signal reaches its maximum values, with a good reading arc compared with other positions. Only the width of reading arc is larger at $11.5 \mathrm{~cm}$, but the values of receiving signal are smaller. This bottle was chosen to represent the experiment as the results for the previous combinations of tags and bottles clearly center the best position in the same place, both in terms of reading arc and power received. So, the results for the mentioned bottle were more interesting to remark because the best position was not the same for the two factors to be considered.

\section{Conclusions}

In this paper, the use of RFID technology is analyzed for implementing traceability at beverage factories, where the ambience is not electromagnetically friendly. The main concepts of such systems are introduced.

Then, different problems related to radio wave propagation are analyzed and evaluated by means of measurement campaigns performed around metallic tanks and wine bottles. An especial care is taken in comparing the performance of the RFID tags when the material under discussion is not present (the metallic tanks or the wine inside the bottle), as it reinforces the idea of the degradation observed by comparing both situations.

\section{Acknowledgments}

This work has been supported by the European Commission (CIP-Pilot Actions), under the project "RFID from Farm to Fork," Grant agreement no. 250444. Research is supported by the European Regional Development Fund (ERDF) and the Galician Regional Government under Project CN 2012/260 "Consolidation of Research Units: AtlantTIC."

\section{References}

[1] J. Landt, “The history of RFID," IEEE Potentials, vol. 24, no. 4, pp. 8-11, 2005.

[2] RFID-F2F (RFID From Farm to Fork), http://www.rfid-f2f.eu/.

[3] ASPIRE, "Advanced Sensors and light weight Programmable Middleware for Innovative RFID Enterprise applications," http://www.fp7-aspire.eu/rfid/sme/.

[4] eTrace, http://www.tracefood.org/index.php/International: SAFEFOODERA_eTrace.

[5] EPCglobal standard for the Electronic Product Code, http:// www.gs1.org/epcglobal.

[6] J. Virtanen, J. Virkki, A. Z. Elsherbeni, L. Sydänheimo, and L. Ukkonen, "A selective ink deposition method for the cost-performance optimization of inkjet-printed uhf rfid tag antennas," International Journal of Antennas and Propagation, vol. 2012, Article ID 801014, 9 pages, 2012.

[7] N. Mai, S. G. Bogason, S. Arason, S. V. Árnason, and T. G. Matthíasson, "Benefits of traceability in fish supply chainscase studies," British Food Journal, vol. 112, no. 9, pp. 976-1002, 2010.

[8] M. Trebar, A. Grah, A. A. Melcon, and A. Parreno, "Towards RFID traceability systems of farmed fish supply chain," in Proceedings of the 19th International Conference on Software, Telecommunications and Computer Networks (SoftCOM '11), pp. 611, Hvar, Croatia, September 2011.

[9] J. Yan, Z. Feng, and D. Jian-Gang, "Research on vegetable traceability system based on internet of things and its application," Research Journal of Applied Sciences, Engineering and Technology, vol. 5, no. 8, pp. 2520-2526, 2013.

[10] P. V. Nikitin and K. V. S. Rao, "Performance limitations of passive UHF RFID systems," in Proceedings of the IEEE Antennas and Propagation Society International Symposium (APS '06), pp. 1011-1014, Albuquerque, NM, USA, July 2006.

[11] F. Fuschini, C. Piersanti, L. Sydanheimo, L. Ukkonen, and G. Falciasecca, "Electromagnetic analyses of near field UHF RFID systems," IEEE Transactions on Antennas and Propagation, vol. 58, no. 5, pp. 1759-1770, 2010.

[12] A. L. Guido, L. Mainetti, and L. Patrono, "Evaluating potential benefits on the use of RFID, EPCglobal, and ebXML in the pharmaceutical supply chain," International Journal of Healthcare Technology and Management, vol. 13, no. 4, pp. 198-222, 2012.

[13] L. Catarinucci, R. Colella, M. de Blasi, L. Patrono, and L. Tarricone, "Enhanced UHF RFID tags for drug tracing," Journal of Medical Systems, vol. 36, no. 6, pp. 3451-3462, 2012.

[14] L. Catarinucci, R. Colella, M. de Blasi, L. Patrono, and L. Tarricone, "Experimental performance evaluation of passive UHF RFID tags in electromagnetically critical supply chains," Journal of Communications Software and Systems, vol. 7, no. 2, pp. 59-70, 2011.

[15] EPC Information Services (EPCIS) Version 1.0.1 Specification, 2007, http://www.gsl.org/gsmp/kc/epcglobal/epcis/epcis_1_0_1standard-20070921.pdf. 
[16] Fosstrak, Open source RFID platform, https://code.google. $\mathrm{com} / \mathrm{p} /$ fosstrak/.

[17] M. Alonso and E. Finn, Fundamental University Physics. Vol II: Fields and Waves, Addison-Wesley Publishing Company, Reading, Mass, USA, 1967.

[18] T. S. Rappaport, "Characterization of UHF multipath radio channels in factory buildings," IEEE Transactions on Antennas and Propagation, vol. 37, no. 8, pp. 1058-1069, 1989.

[19] P. V. Nikitin, D. D. Arumugam, M. J. Chabalko, B. E. Henty, and D. D. Stancil, "Long range passive UHF RFID system using HVAC ducts," Proceedings of the IEEE, vol. 98, no. 9, pp. 1629$1635,2010$.

[20] Y. Zhang, K. Yemelyanov, X. Li, and M. G. Amin, "Effect of metallic objects and liquid supplies on RFID links," in Proceedings of the IEEE International Symposium on Antennas and Propagation and USNC/URSI National Radio Science Meeting (APSURSI '09), Charleston, SC, USA, June 2009.

[21] Confidex Halo Product Datasheet, Confidex Limited, January 2010.

[22] AT570 Reference Guide, version 1.1, ATID Company Limited.

[23] K. V. S. Rao, P. V. Nikitin, and S. F. Lam, "Antenna design for UHF RFID tags: a review and a practical application," IEEE Transactions on Antennas and Propagation, vol. 53, no. 12, pp. 3870-3876, 2005.

[24] M. E. de Cos and F. Las-Heras, "Dual-band antenna/AMC combination for RFID," International Journal of Antennas and Propagation, vol. 2012, Article ID 804536, 7 pages, 2012.

[25] P. V. Nikitin and K. V. S. Rao, "LabVIEW-based UHF RFID tag test and measurement system," IEEE Transactions on Industrial Electronics, vol. 56, no. 7, pp. 2374-2381, 2009.

[26] ALR-9900+EMA, Enterprise RFID Reader, Alien Technology, 2012.

[27] ALR-8611-C, High Performance RFID Antenna, Alien Technology, 2009. 

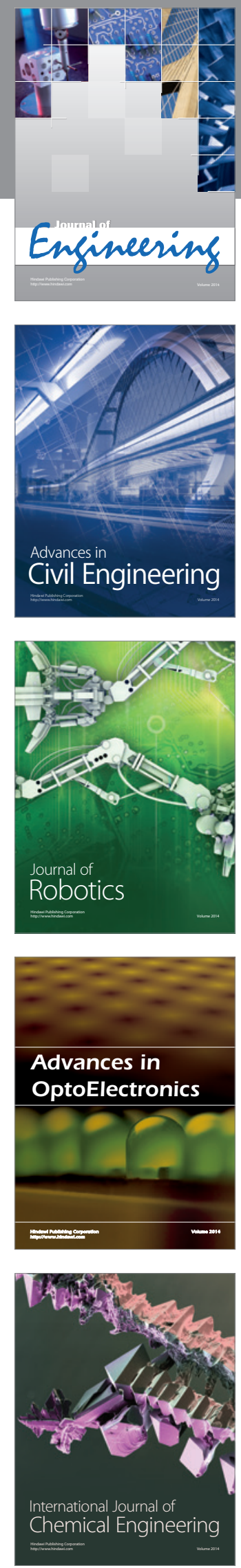

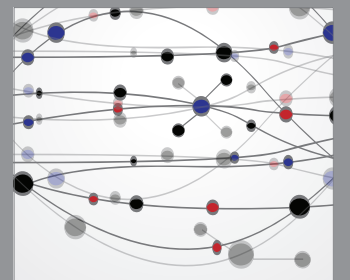

The Scientific World Journal
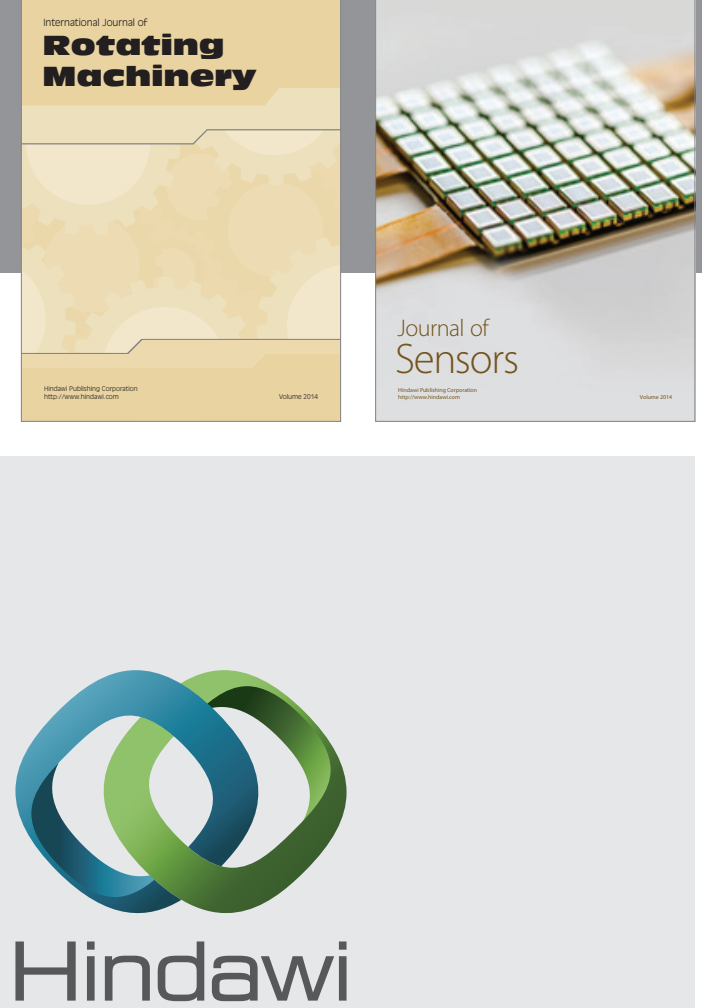

Submit your manuscripts at http://www.hindawi.com
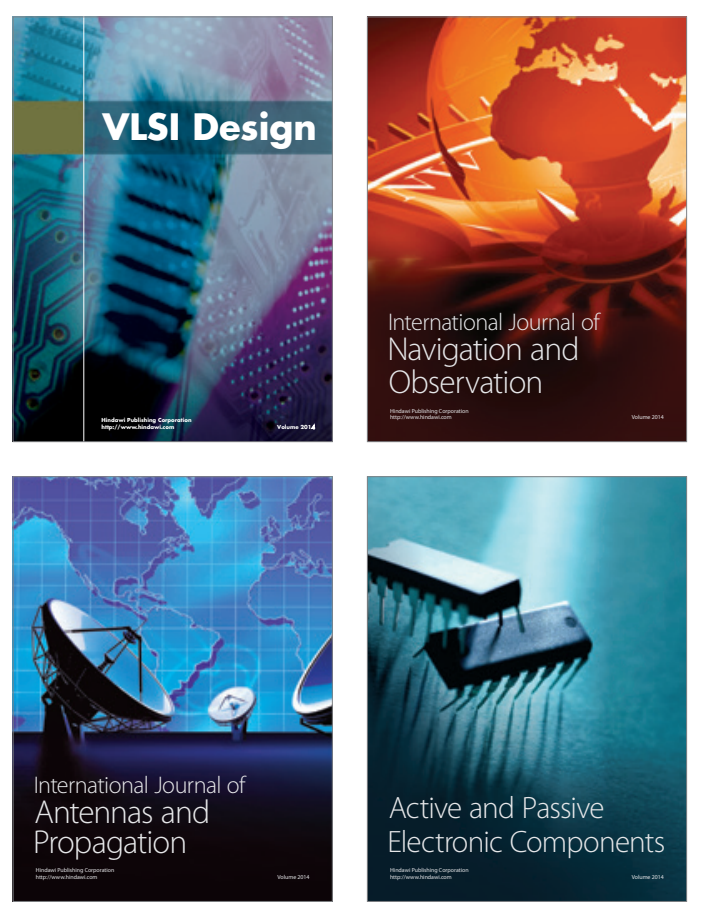
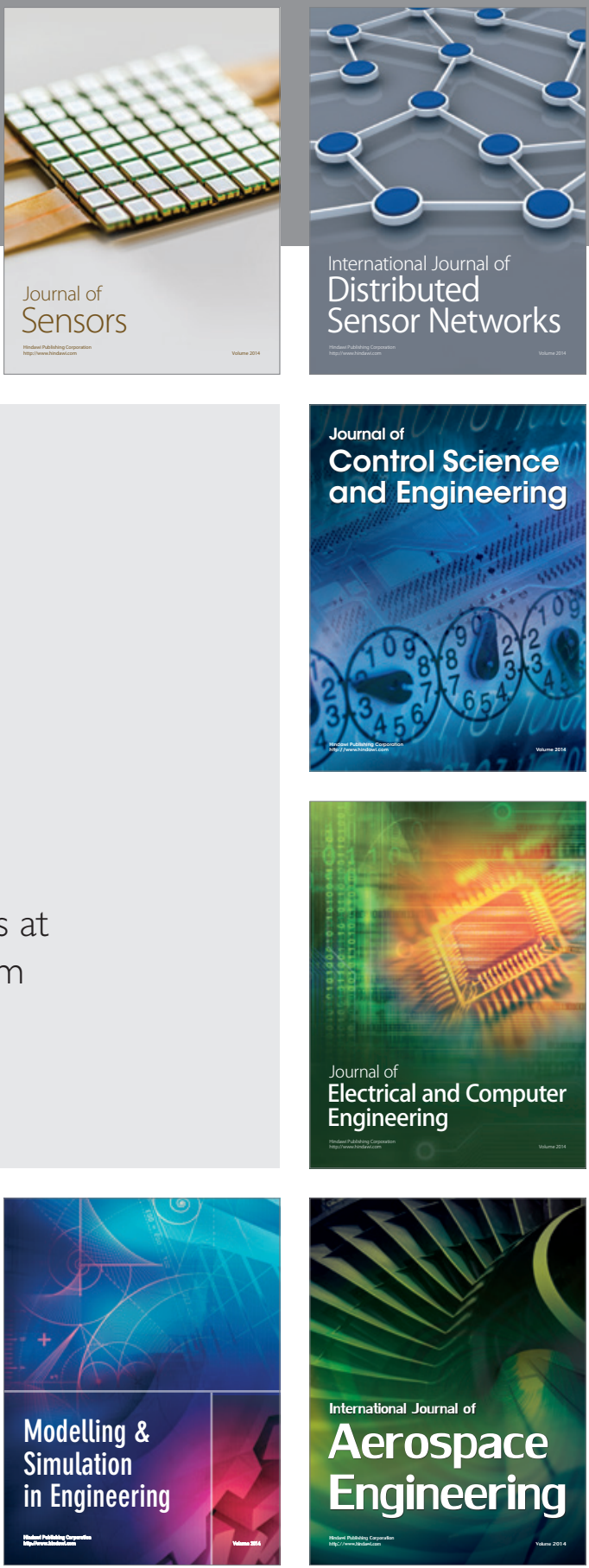

Journal of

Control Science

and Engineering
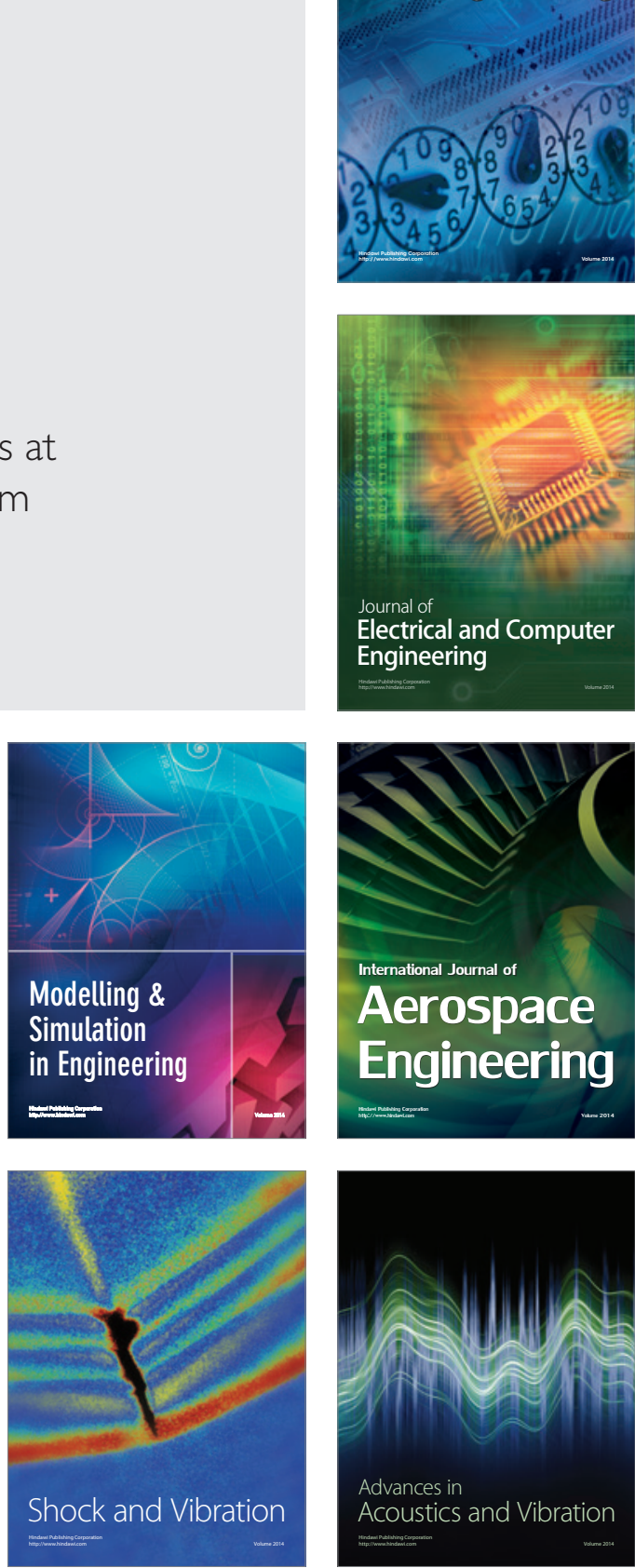